\title{
William Lawrence Bragg
}

\author{
1890-1971
}

Sir Lawrence Bragg died on 1 July 1971. He was one of the greatest of modern scientists, and I, as one of his early research students, am grateful for this opportunity of paying a tribute to him. Fortunately, several of us were given such an opportunity when we were invited to contribute to the Festschrift issue of Acta Crystallographica in 1970, which celebrated his 80 th birthday; then we were pleased that he could read what we wrote about him. Since so much was then written, a great deal more can hardly be added. The length of this obituary notice is therefore no measure of his greatness or of the esteem in which he was held.

His death marks the end of an era. It is not often that one man can be said to have originated and established completely an important section of science, but this is exactly what Bragg did. When he started research, the atomic theory was accepted but the possibility of examining the behaviour of individual atoms seemed hopelessly remote; by the end of his lifetime scientists in all branches of science were engaged in minute examination of atomic arrangements, some of them of almost unbelievable complexity. As a young man he found the structure of $\mathrm{NaCl}$; as an old man he inspired the workers who disentangled the structures of the proteins.

He never lost sight of the fact that he was a physicist. He placed physical insight and understanding before theoretical manipulation. He was always concerned with the basic physical principles behind the work that he was doing, when so many other people were content just to use the formulae that he and others had developed. It was he who introduced the term 'The New Microscopy' for his research work, and there is little doubt that this passion for optics - the ionization spectrometer, the diffraction of short electromagnetic waves, Fourier synthesis as an optical image, the X-ray microscope - coloured all his work and helped to keep him in the forefront of it all his life.

One of his early ambitions was to make a photographic image of a crystal structure. First he used crude shadows of wires on photographic paper, and later the much neater process of diffraction from a reciprocallattice plate. There was no pretence that this would be a great step forward; to him it was a challenge and to accept the challenge was fun.

Bragg had two great qualities as a scientist. First, he had the gift of inspiring others, as he himself was inspired with a love of optics by C. T. R. Wilson. It can fairly be said that almost all the crystallographic laboratories in the world stem either from the people who have worked with him in Manchester and Cambridge, or from those who worked with his father in the Royal Institution in London. It is not given to many people to see such a spread of their work during their lifetime.

Secondly, he could see with uncanny clarity what fields of science could benefit from the application of his methods. This knack stayed with him the whole of his life. As soon as he had established the principles of crystal-structure determination, and had applied them to some simple inorganic structures, he left to others what might have seemed like his life's work, and turned to the more mystifying field of minerals. As soon as he had laid the fundamentals of this, he turned his attention to metals, and, with the help of A. J. Bradley, uncovered a range of problems there. When he had satisfied himself that these were tractable, he left them for the still more remote fields of living matter - the proteins. His success in this operation, with Perutz and Kendrew, needs no further telling. Those of us who privately prophesied failure were confounded; we had not envisaged the advent of digital computers and automatic diffractometers which made success possible. Neither, of course, had Bragg. But he knew that science thrives on tackling the apparently impossible and that new ideas have the habit of turning up at opportune moments. His life was the perfect answer to those who believe that a scientist, having perfected a technique, is wasting his talents if he does not go on using it; he believed that when one is in sight of perfection one should then try something else!

This obituary notice would be incomplete without some reference to Bragg as a man. He was not, in any sense at all, what the world would regard as a typical scientist; his reasoning was rarely deductive, in which one arrives at an answer to a problem by logical steps from a given premise: his method was to guess at the right answer and then set about finding whether he was right. Usually he was, and this was his great gift. But sometimes he was wrong, and he was always ready to admit his misjudgments and then to learn from them to push his ideas further.

For these reasons, he was always approachable. Since he was not dogmatic, he was always prepared to discuss his ideas with anybody - even the newest of the research students in his department. Such discussions were always as man to man, not as master to disciple: but there was no doubt who benefited most from them!

It is usual to say, when a great man dies, 'He will be sorely missed'. This is not true of Bragg. His influence has pervaded so much of science that it will always be difficult to remember that he is no longer with us. His fund of ideas and his influence in so many fields will serve to inspire many of us throughout the rest of our lifetimes.

H. LIPSON 


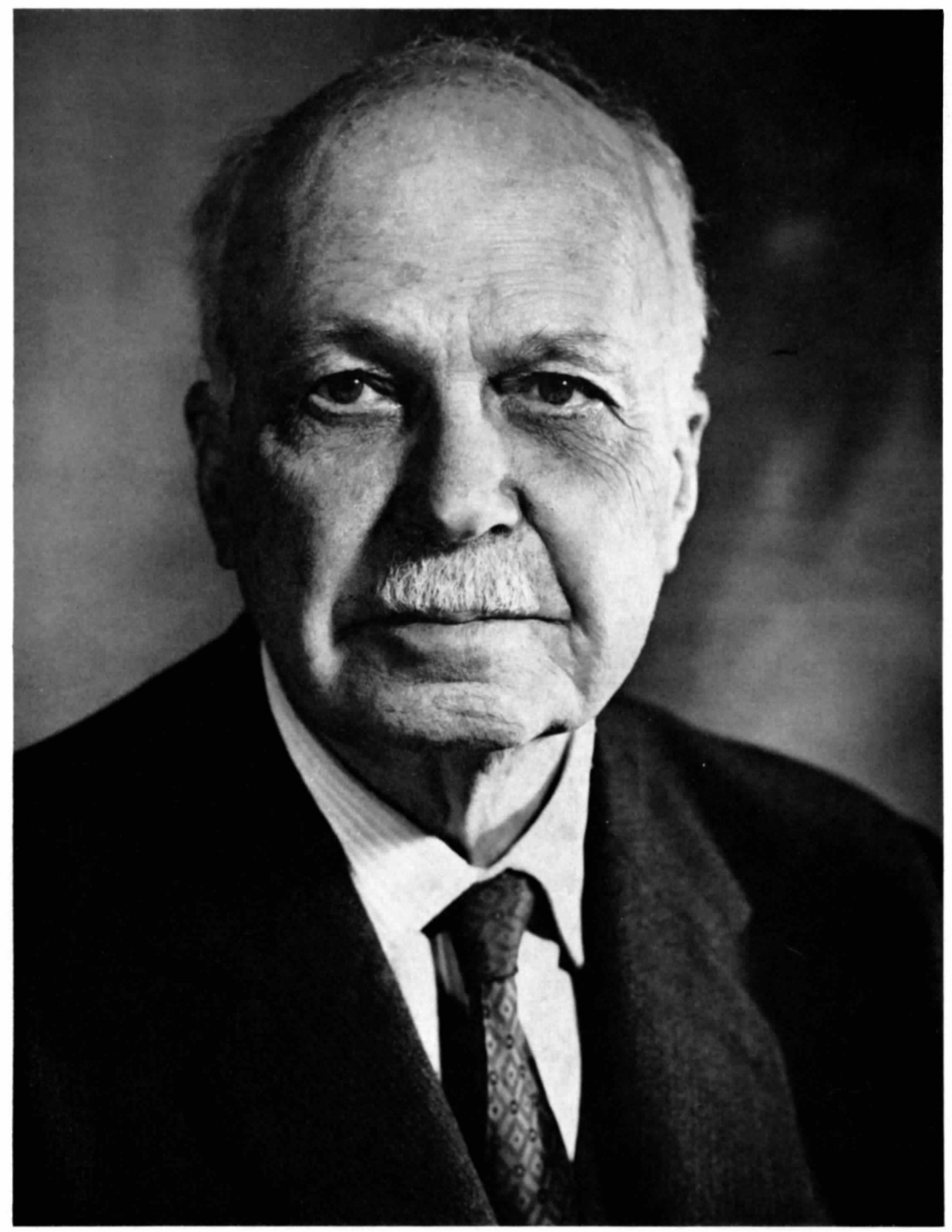

SIR LAWRENCE BRAGG $1890-1971$ 